\title{
Hunting by Scent
}

The Mystery of Scent

By Hugh B. C. Pollard. Pp. xix + 139. (London : Eyre and Spottiswoode, Ltd., 1937.) 10s. 6d. net.

7 HE vagrant nature of odours would seem to be symbolized by a word-errant in search of a meaning. Scent, for example, according to a dictionary, signifies "odoriferous particles, odour, smell, fragrance ; a class or one of a class of sweetsmelling, aromatic substances used for perfuming ; sense of smell; odour left by the animal on the ground or surface passed over". It is the latter meaning that is mainly implied in the title of Major Pollard's book. He discusses principally the relatively complex conditions which control the diffusion of scent, and has worked out a simple instrument which will tell the hunting man the chance of scent on any day.

It is claimed to be a practical book for foxhunting people rather than a scientific discourse. However, a racy style does not altogether mask the large quantum of science lurking in its pages ready to engage the attention of the reader and to exact his interest. The expert in ballistics proves himself to be also an adept in firing data and problems, physical, chemical and biological.

The correlation between scenting and meteorological conditions was discussed from different points of view in "Hunting by Scent" by $\mathrm{Mr}$. Budgett. (NATURE, 133, 548-549; 1934), and in a pamphlet on "Scent and the Weather" by FlightLieut. Veryard (NATURE, 136, $60 ; 1935$ ). Major Pollard explains the development of a relatively large volume of scent from the small amount secreted by the pad glands of the fox, by suggesting that fox scent is an extremely volatile compound with marked capacity for spreading on water as a monolayer and being dissipated on water vapour. There are good reasons for doubting that the foxy (fur or bedding) scent we know is what hounds really hunt. 'The true 'scent' or pad secretion at each footstep is small, but on a still day the emanation from a series of pad marks was observed to form a band 15-20 yards broad, and, on a windy day, hounds are able to pick up a line even on a broader front.

The best scenting conditions prevail when the evaporation near the surface of the ground is at its maximum. The range and variation of the meteorological factors on a normal hunting day are much wider than is usually realized. No one factor alone controls scenting. The 'Pollard scentometer' (Prov. Pat. No. 26346), which is now marketed by the publishers, raises the prediction of hunting conditions in the course of the day from intelligent guesswork to a reasonable degree of fore-knowledge. The instrument comprises a thermometer, hygrometer, and an arrangement of five circular concentric dials which are set to the temperature, degree of humidity, relative amount of cloud, quarter of the wind, and wind velocity. The lower part of each dial is provided with numerical values for scent, which are read between two parallel wires and added up from the bottom to the centre. The sum represents the percentage of scent to be expected within the next few hours.

Major Pollard has also much of interest to relate about scent in other animals, about scent and local conditions, and a number of other problems, new and old, and all discussed in a stimulating manner. His book should certainly stimulate further research on such problems as that of adsorption and on the electrical phenomena in odorous vapours, and also the comparative study of the role of pigments in the olfactory mucous membrane and cognate subjects. J. H. K.

\section{Plant Physiology for Students}

General Plant Physiology

By E. C. Barton-Wright. Pp. 539. (Williams and Norgate, Ltd.) 15s. net.

DLANT physiology-especially the teaching of it-has not been in a satisfactory state for decades, and though one is constantly looking for signs of improvement, prospects are not reassuring. It seems worthy of reflexion that the first-class plant physiologist of the future must be the almost exclusive enthusiast of the present; for few ordinarily promising students are being attracted to the subject.

Until recently, one of the apparent reasons for this was the dearth, in fact, absence, of text-book reading for elementary students. There were no British text-books of university first degree standard, and the few American books, though worthy, seemed quite unknown. Students were 